\title{
TIME FACTOR AND THE ROLE OF GASTROSTOMY TUBE PLACEMENT IN THE TREATMENT OF ADVANCED HEAD AND NECK TUMORS
}

\author{
Hajtmanova E. ${ }^{1}$, Hajtman A. ${ }^{2}$, Pec M. ${ }^{3}$, Kinclova I. ${ }^{1}$, Murin P. ${ }^{1}$, Hajtman A. Jr. ${ }^{4}$
}

${ }^{1}$ Oncology Center, University Hospital Martin, ${ }^{2}$ Department of Otorhinolaryngology, Head and Neck Surgery, ${ }^{3}$ Department of Biology, Jessenius Faculty of Medicine, Comenius University and University Hospital Martin, ${ }^{4}$ Healthcare Surveillance Authority, Martin, Slovak Republic

\begin{abstract}
Aim: Time factor in the treatment of advanced head and neck tumors undoubtedly affects local tumor control and overall survival of treated patients. The aim of this work was to analyse individual time periods of radiation therapy, emphasising the role of enteral nutrition via gastrostomy tube (GT).

Methods: Patients with cancer of head and neck region are in $70-80 \%$ cases diagnosed in locally advanced stage; the majority of cases are complicated by various degrees of malnutrition. Radiation therapy of malignancies in the head and neck region is accompanied by considerable acute toxicity, manifested by severe odynophagia, dysphagia, xerostomia and/or dysgeusia. Toxicity of chemoradiotherapy worsens the unfavourable nutritional state of patients and it often causes unplanned treatment gaps. Prophylactic GT placement effectively mitigates adverse effects of radiation therapy. In the retrospective analysis of 83 patients, the effect of GT on individual intervals of concomitant chemo-radiotherapy was evaluated. We focused on the time interval between diagnosis and the beginning of the treatment. Next, the length of treatment gaps, caused by acute toxicity, was compared between the two groups of patients - without GT and with GT. Finally, body weight loss during the treatment and overall survival were compared in these two groups of patients.

Results: The time interval diagnosis-chemoradiotherapy for patients diagnosed and treated in University Hospital Martin (UNM) was on average 35.1 days, compared to 49.6 days for patients who were diagnosed in other hospitals and treated in UNM. Toxicity of radiotherapy in the treatment of patients with malignancies in the head and neck region is associated with a high risk of treatment interruptions. Treatment gaps caused by acute radiotoxicity were on average 4.1 days for patients with inserted GT, compared to 6.8 days for patients without GT. Weight loss was on average $4.4 \mathrm{~kg}$ for patients with GT, compared to $7.0 \mathrm{~kg}$ in the reference group of patients without GT. Median survival in the group of patients with GT and without GT was 787 and 366 days, respectively.

Conclusion: The results of retrospective study confirm that gastrostomy tube placed before the start of radiotherapy treatment markedly affects the time intervals in the treatment of head and neck cancers. It reduces undesired gaps in concomitant chemoradiotherapy and consequently it improves overall survival. Gastrostomy tube nutrition is an established method to provide patients with enteral nutrition and hydratation during manifestations of chemoradiotherapy toxicity, which means reduction of weight loss during the treatment, improvement of morbidity, less frequent need for parenteral support treatment - so that the majority of patients can undergo an outpatient treatment and retain an adequate quality of life.
\end{abstract}

Key words: advanced head and neck tumors, surgical gastrostomy, percutaneous endoscopic gastrostomy (PEG), chemoradiotherapy

Address for correspondence:

Eva Hajtmanová, MD., PhD., Oncology Center, University Hospital Martin, Kollarova Str. N. 2, 03659 Martin, Slovakia, tel.: +421-43-420 39 16, e-mail: hajtmanova@mfn.sk. 


\section{INTRODUCTION}

Malignant tumors in the head and neck region are among the most frequent malignant diseases and causes of death from malignant diseases (1). 75 - $80 \%$ of patients are diagnosed in locally advanced stage which is characterised by local growth and metastasing via lymphatic system. Patients with such an advanced disease have poor prognosis - 5-year survival rate is 20-30\% (2). In the treatment of early stages of the disease, one of these treatment modalities is indicated: surgery or radiotherapy. Treatment of patients with advanced stage of the disease comprises a combination of surgery, radiotherapy, chemotherapy and biological therapy. Combination of therapeutic modalities however, means not only higher local control, but also a higher toxicity. This is stressed by the fact that patients with cancers in the upper part of aerodigestive tract already have a high risk of malnutrition at the time of diagnosis. Subsequent multimodality treatment further worsens their unfavourable nutritional state (3). The reasons of nutrition disorders include swallowing problems, caused by the cancer and side effects of radiotherapy/concomitant chemoradiotherapy.

Irradiation of tumors in the head and neck region causes acute reactions in mucosa in the mouth cavity, larynx and cervical part of esophagus. These reactions include erythema, ulcerations, pseudomembranes and tissue necrosis. At the same time, the taste buds are affected; the patient suffers from dysgeusia or ageusia. Irradiation of salivary glands causes various degrees of xerostomia (4). Mucositis worsens odynophagia and increases the risk of infections. Acute radiation toxicity arises during the treatment and lasts up to three months after the treatment. If the treatment regime is intensified, acute toxic changes may last even longer (5). Severe mucositis often causes prolongation of oncologic treatment (6). If the treatment gaps last longer than one week, they cause statistically significant decrease of tumor local control and worsen overall survival (7).

Treatment response is adversely affected by poor nutritional state of patients, which is caused not only by treatment toxicity, but also by cancer localization, which makes peroral food intake difficult or even impossible. Enteral nutrition via gastrostomy tube (GT) is suitable to sustain nutritional status of patients treated by chemoradiotherapy. In comparison to parenteral nutrition it has an advantage of keeping the integrity and functioning of bowel and supporting the immune system. Prophylactic gastrostomy tube placement before the start of the treatment ensures supportive treatment and adequate hydratation. Early placement of probe nutrition prevents from massive body weight loss during oncologic treatment and minimizes the risk of its prolongation. Reduction of complications based on malnutrition and less need for parenteral nutrition means that the majority of patients can undergo an outpatient treatment $(8,9)$.

Since 2006, patients with locally advanced T3-T4 tumors of head and neck region treated at Oncology Centre of University Hospital Martin (UNM) have had placed prophylactic GT. These patients had the indication of postoperative radiotherapy or curative chemoradiotherapy of inoperable tumors. The most optimal was percutaneous endoscopic gastrostomy (PEG) tube placement during hospitalisation at the Department of Otorhinolaryngology, Head and Neck Surgery, Jessenius Faculty of Medicine of Comenius University and UNM Martin (further referred to as DOHNS Martin), directly after diagnosis and histological verification of cancer. In the case that a gastroscope could not be inserted or there was a risk of organ interposition between stomach and the abdominal wall, percutaneous laparoscopically assisted gastrostomy (PLAG) was performed (10). The aim of retrospective analysis was to evaluate the length of individual time intervals of chemoradiotherapy and the effect of prophylactic GT on unplanned treatment 
gaps, which were caused by treatment toxicity. We evaluated the nutritional state of patients with GT and without GT in connection with change of their body weight loss during the treatment. Overall survival (OS) time was used to assess the results of the treatment.

\section{PATIENTS AND METHODS}

From January, 2004 to May, 2010, 226 patients with locally advanced spinocellular carcinoma of head and neck were treated at Oncology Centre UNM. A group of 83 patients with malignancies in the head and neck region was included into a retrospective study. Patients with malignant tumors of nasopharynx, larynx, salivary glands and paranasal sinuses were not included into the study. Another exclusion criterion was total radiation dose to primary tumor lower than 58.0 Gy and treatment gaps from other reasons than treatment toxicity (public holidays, technical problems with a treatment machine, etc.) with overall length longer than 5 days. Several patients, treated during Christmas and New Year were left out because of long treatment gaps between the mentioned holidays - patients refused to come to treatment sessions.

Patients had histologically confirmed spinocellular carcinoma G1 to G3. Performance status according to Karnofsky score was $\geq 70$. In January 2006, we introduced placement of gastrostomy tubes in cooperation with DOHNS Martin and Division of Gastroenterology at the 1st Department of Internal Medicine, Jessenius Faculty of Medicine of Comenius University and UNM. Patients included in the study had GT implanted before the start of concurrent chemoradiotherapy.

69 patients were treated by concurrent chemoradiotherapy as a single modality. Surgical resection of primary tumor with various degrees of success and lymphnode resection was used in 14 patients. A linear accelerator with $6 \mathrm{MV}$ high-energy photon beams was used for irradiation. The treatment technique comprised three asymmetric fields up to the total dose of radiation $44-50 \mathrm{~Gy}$; subsequently the treated volume was reduced due to toleration dose of the spinal cord. The planned total dose of radiation (cTD) for patients without surgical treatment or those with subradical resection was 68-70 Gy and applied cTD ranged from 5870 Gy. For patients who underwent radical resection, planned cTD was 60-64 Gy and applied cTD ranged 56-64 Gy. All patients were treated with standard regime once a day five days per week. Concurrent chemoradiotherapy was applied in the CDDP regime $40 \mathrm{mg} / \mathrm{m}^{2}$ weekly, with adequate hydratation and premedication by setron antiemetics. Table 1 shows the summary of patient characteristics. 
Table 1 Patient characteristics

\begin{tabular}{|c|c|}
\hline Characteristics & Number of patients ( $n, \%)$ \\
\hline \multicolumn{2}{|l|}{ Gender } \\
\hline Men & 76 (91.6\%) \\
\hline Women & 7 (8.4\%) \\
\hline \multicolumn{2}{|l|}{ Age (years) } \\
\hline Median & 55 \\
\hline Range & $41-75$ \\
\hline \multicolumn{2}{|c|}{ Primary tumor localisation } \\
\hline Tonsilla & $3(3.6 \%)$ \\
\hline Hypofarynx & $20(24.1 \%)$ \\
\hline Tongue & $1(1.2 \%)$ \\
\hline Tongue root & $3(3.6 \%)$ \\
\hline Pharynx & $9(10.8 \%)$ \\
\hline Laryngopharynx & 19 (22.9\%) \\
\hline Oropharynx & 27 (32.5\%) \\
\hline Inner lip & $1(1.2 \%)$ \\
\hline \multicolumn{2}{|c|}{ Clinical T-staging of tumor } \\
\hline $\mathrm{T} 1$ & $3(3.6 \%)$ \\
\hline $\mathrm{T} 2$ & $8(9.6 \%)$ \\
\hline T3 & $34(41.0 \%)$ \\
\hline $\mathrm{T} 4$ & $38(45.8 \%)$ \\
\hline \multicolumn{2}{|c|}{ Clinical N-staging of tumor } \\
\hline NO & 7 (8.4\%) \\
\hline $\mathrm{N} 1$ & $26(31.3 \%)$ \\
\hline $\mathrm{N} 2$ & $43(51.8 \%)$ \\
\hline N3 & $6(7.2 \%)$ \\
\hline NX & $1(1.2 \%)$ \\
\hline \multicolumn{2}{|l|}{ Stage } \\
\hline III & 17 (20.5\%) \\
\hline IV & 66 (79.5\%) \\
\hline \multicolumn{2}{|c|}{ Gastrostomy tube placement } \\
\hline with GT & $44(53.0 \%)$ \\
\hline no GT & 39 (47.0\%) \\
\hline \multicolumn{2}{|l|}{ Diagnostics } \\
\hline In UNM Martin & 56 \\
\hline In other hospitals & 27 \\
\hline
\end{tabular}


Patients treated by concurrent chemoradiotherapy were followed-up for 6 - 37 months (median; 24 months). Locoregional tumor control was assessed one month after completion of treatment by otorhinopharyngeal (ORL) inspection and ultrasound; and two months after treatment completion by CT inspection. Subsequent ORL inspections were repeated in 2 to 3-month intervals. Following CT and ultrasound inspections were indicated according to the health status of each individual patient. Locoregional failure was confirmed by a biopsy.

\section{Methods of analysis}

Input values for analysis were documented in frequency tables. Kaplan-Meier method and survival curves were used for calculation of overall survival (it was calculated from the time of chemoradiotherapy treatment completion). The effect of various variables was evaluated by Mantel-Cox log-rank test which is usually used for calculation of censored data. All $p$-values represent results of these statistical tests. Values $p<0.05$ were considered as statistically significant.

Values of arithmetic mean, standard deviation (SD) and range were computed for the analysis of weight loss, treatment gaps and interval diagnosis-chemoradiotherapy. Significance of difference between arithmetic means was computed by one-way ANOVA, in this case we used a significance level of 0.01 .

Application SPSS/PC Software package, version 17.0 was used for data processing and statistical analysis.

\section{RESULTS}

The overall time of follow-up was 37 months. Median survival in the study group of patients treated by concurrent chemoradiotherapy was 17 months (512 days). During the last follow-up (37 months) $30.9 \%$ patients were alive.

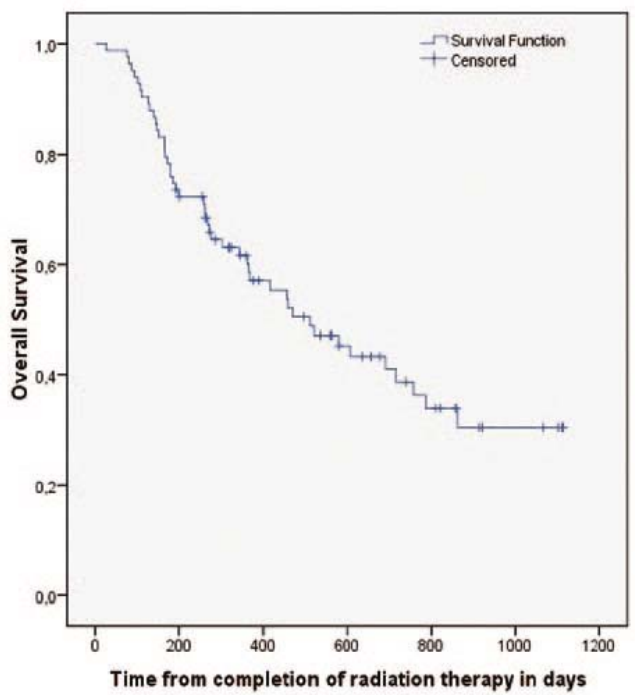

Fig. 1 Overall survival in the group of patients with advanced malignant head and neck tumors

Statistical comparison of survival curves for the two groups of patients - patients without GT and patients with GT shows better survival rate for patients with GT. Median survival was 787 days for patients with GT, compared to 366 days for patients without GT. Overall 3-year survival for patients with GT and without GT was $47.8 \%$ and $20.5 \%$, respectively. The log-rank test shows that the difference is statistically significant ( $p=0.037$ ). 


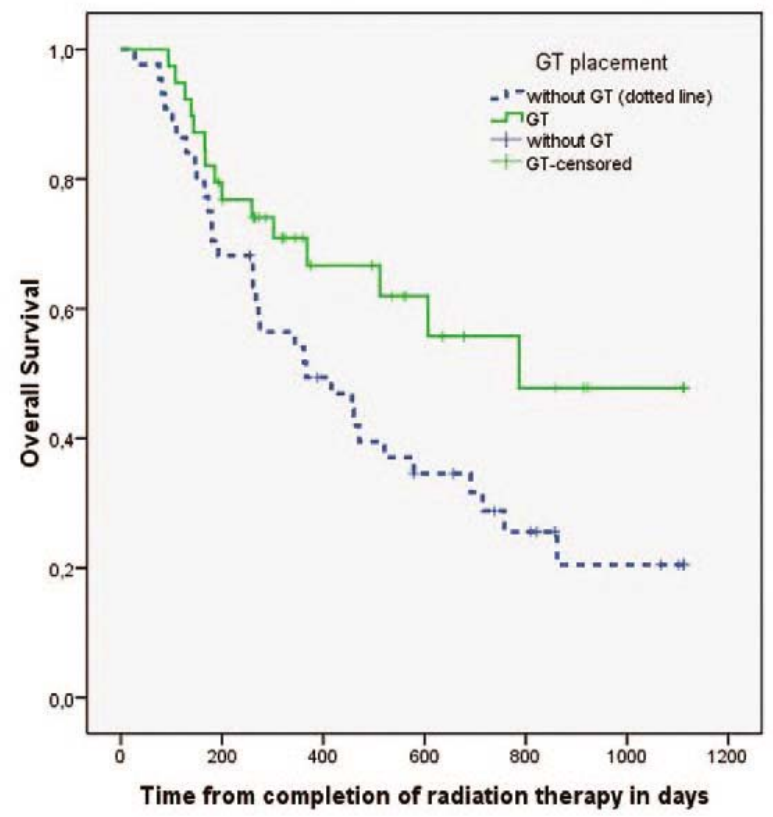

Fig. 2 Kaplan-Meier survival curves for patients with GT (solid line) and patients without GT (dotted line)

The time interval from the time of diagnosis to the start of planned chemoradiotherapy was on average 35.1 days (range: 15-59 days, SD: \pm 14.3 days) for patients who were diagnosed in UNM and underwent GT placement in the same hospital. For patients diagnosed in other hospitals, the planned treatment started on average 49.6 days after diagnosis (range: 11-115 days, SD: \pm 20.4 ). The difference between these two means was statistically significant.

The treatment gaps caused by toxicity lasted on average 4.1 days for patients with GT (range: 0-12 days, SD: \pm 3.1 ) and 6.8 days for patients without GT (range: 0-18 days, SD: \pm 3.8 days). The difference between these two means was statistically significant.

Average body weight loss (the difference of body weight before and after treatment) was $7.0 \mathrm{~kg}$ for patients without GT (range: $4-21 \mathrm{~kg}$, SD: $\pm 3.0 \mathrm{~kg}$ ), compared to $4.4 \mathrm{~kg}$ for patients with GT (range: 0-12 kg, SD: \pm 2.7 ). The difference between the two means was statistically significant.

\section{DISCUSSION}

The importance of time factor in radiotherapy for spinocellular carcinoma in the head and neck region is documented by many published studies. Prolongation of time period from diagnosis to the start of the treatment, from the surgery to start of chemoradiotherapy and prolongation of actual radiotherapy has an unfavourable effect on local control of malignant tumor and survival of patients (11). Prolongation of these time periods can be on various reasons - these include radiotoxicity, technical problems with a treatment machine, or public holidays. GT placement before the start of the treatment has an influence on all time periods of the treatment.

Jensen et al. analysed the effect of time period between malignant tumor diagnosis and the beginning of the treatment (12). In the group of 648 patients treated for spinocellular carcinoma in the head and neck region, relationships between waiting time for the treatment, primary tumor volume and regional lymphnode status were evaluated. 
During the average waiting time for the treatment in the duration of 4 weeks, in 62 patients a measurable increase of tumor volume was noticed, in $20 \%$ patients the tumor made progress into regional lymphnodes, which in $16 \%$ patients meant increased TNM staging. Also, in a retrospective study which focused on time factor in postoperative radiotherapy, Suwinski et al. (11) pointed out adverse effect, prolongation of time period between surgery and the start of radiotherapy had on the treatment outcome. Analysis of Ang et al. (13) assumed that increase of the interval to 90 days may worsen 5 -year progression survival rate by approximately $15 \%$.

Waiting times for treatment were in our group of patients longer for patients diagnosed outside UNM. GT insertion was realized at our hospital, which contributed to the delay. Thanks to active cooperation with several ORL departments many patients come to the treatment with GT already applied.

The most time-saving solution was GT placement at DOHNS Martin, which was done immediately after diagnosis of malignat tumor or during a surgical treatment. Among other advantages of GT placement at ORL Department is a possibility to combine the GT placement with other procedures, for example panendoscopy, tracheostomy and subsequent biopsies (14), which proved effective at UNM, too.

Many published works confirm worsening of local tumor control in the head and neck region by prolongation of overall treatment time (OTT) of radiotherapy or concurrent chemoradiotherapy. Decrease in local control after prolongation of OTT by a week is according to Saarilahti $12-18 \%(15)$.

Accelerated repopulation of clonogenic cells in the malignant tumor is supposed to be the principal reason of radiotherapy failure. In spinocellular carcinomas of head and neck region it begins on the 21st to 28th day of the treatment and every day of treatment prolongation after this period means a decrease in treatment efficacy, which can be expressed in the loss of irradiation dose by approximately 0.6 to 0.9 Gy per every fraction of radiation $(6,11)$. That's why Radiation Oncologists aim to shorten the overall treatment time by alternative fractionation schedules and at the same time by minimising treatment gaps. Insertion of GT before the start of the treatment is a simple and safe method that decreases the probability of treatment gaps caused by acute radiotoxicity. Sometimes patients refuse GT despite the recommendation and they agree with this method of enteral nutrition only after escalation of complications. Gastrostomy placement during the treatment means further prolongation of the treatment; on the other hand it allows treatment continuation. Prophylactic GT placement undoubtedly reduces unplanned treatment gaps and influences the survival of patients. It is confirmed by this retrospective study - a statistically significant favourable effect of GT placement on 3-year survival.

Complete enteral nutrition through the GT was fully used from the start of the treatment by two patients from the analysed group. Malignant tumor was a mechanical obstruction which prevented food intake. The other patients fully used GT only during the escalation of radiation toxicity. The decrease of body weight which was recorded in $93 \%$ of patients was similar to $89 \%$, given in the study of Connor et al (16). Body weight loss during the treatment was $4.4 \mathrm{~kg}$ for patients with GT, compared to $7.0 \mathrm{~kg}$ for patients without GT. The results were, despite a small group of patients, similar to published results - on average $3.1 \mathrm{~kg}$ and $7.0-8.5 \mathrm{~kg}$ for patients with GT and without GT, respectively $(17,18)$.

A simple method of GT handling enabled patients from Martin and its surroundings to undergo an outpatient treatment. Even patients from the lowest social levels managed GT manipulation. Preventive GT placement was defined by Morton et al. (9) as a necessary part of care for patients treated for malignant head and neck tumor, which provided proper treatment and hydration; and acceptable quality of life.

Patients gradually started to take food per os after the treatment when dysphagia subsided. GT was removed for the majority of patients 4 to 6 months after the treat- 
ment. A prerequisite was remission of the disease, confirmed by CT and ORL examination and Karnofsky performance status $\geq 90$. None of the patients had swallowing problems caused by atrophy of swallowing muscles or late pharyngeal strictures that were emphasised by Chen et al. (19). GT was left permanently for patients with persistence of large tumors.

\section{CONCLUSION}

Prophylactic gastrostomy tube placement before the start of chemoradiotherapy treatment of patients with advanced malignant head and neck tumors is a safe and technically simple method to reduce undesired treatment gaps and ensure enteral nutrition and hydration. Because of simple handling of GT at home, many patients can undergo an out-patient treatment. This form of nutrition allows them to maintain a favourable quality of life even in the case that GT is left permanently because of advanced disease.

\section{REFERENCES}

1. Corvó R. Evidence-based radiation oncology in head and neck squamous cell carcinoma. Radiother Oncol 2007; 85(1): 156-170.

2. Mechl Z, Smilek P, Červená R. Současná strategie léčby karcinomů ORL oblasti. Klin Onkol 2008; 21(2): 45-51.

3. Wasiková S, Piskač P, Spurný V, Rotnáglová S. Perkutánní endoskopická gastrostomie u pacientů s tumory hlavy a krku. Klin Onkol 2007; 20(5): 349-353.

4. Petera J, Odrážka K, Zouhar M. et al. Principy radioterapie. In: Šlampa P, Petera J et al. Radiační onkologie. 1st ed. Praha: Galén Karolinum; 2007. p. 11-65.

5. Hynková L, Doleželová H. Nežádoucí účinky radioterapie a podpưrná léčba u radioterapie nádorů hlavy a krku. Onkologie 2008; 2(2): 88-90.

6. Zips D. Influence of time factor and repopulation on treatment resistance. In: Molls M, Vaupel P, Nieder C, Anscher MS. The impact of tumor biology on cancer treatment and multidisciplinary strategies. Berlin: Springer; 2009. p. 292-296.

7. Šlampa P, Soumarová R, Kocáková I. et al. Konkomitantní chemoradioterapie solidních nádorů. Praha: Galén; 2005. 167 p.

8. Rutter CE, Yovino S, Taylor R et al. Early PEG tube placement improves nutritional status and decreases hospitalization in head and neck cancer patients receiving definitive chemoradiation. Int $J$ Radiat Oncol Biol Phys 2009; 75(3)supplement: S123-S133.

9. Morton RP, Crowder VL, Mawdsley R, Ong E, Izzard M. Elective gastrostomy, nutritional status and quality of life in advanced head and neck cancer patients receiving chemoradiotherapy. ANZ J Surg 2009; 79(10): 713-718.

10. Šachlová M: Výživa onkologických pacientů. Klin Onkol 2003; 16(2): 77-79.

11. Suwinski R, Sowa A, Rutkowski T, Wydmanski J, Tarnawski R, Maciejewski B: Time factor in postoperative radiotherapy: a multivariate locoregional control analysis in 868 patients. Int J Radiat Oncol Biol Phys 2003; 56(2): 399-412.

12. Jensen AR, Nelleman HM, Overgaard J. Tumor progression in waiting time for radiotherapy in head and neck cancer. Radiother Oncol 2007; 84(1): 5-10.

13. Ang KK, Trotti A, Brown BW, Garden AS, Foote RL, Morrison WH, Geara, FB, Klocht DW, Goepfert H, Peters LJ. Randomized trial addressing risk features and time factors of surgery plus radiotherapy in advanced head and neck cancer. Int J Radiat Oncol Biol Phys 2001; 51(3): 571-578.

14. Hujala K, Sipilä J, Pulkkinen J, Grenman R. Early percutaneous endoscopic gastrostomy nutrition in head and neck cancer patients. Acta Otolaryngol 2004; 124(7): 847-850.

15. Saarilahti K, Kajanti M, Lehtonen H, Hämäläinen T, Joensuu H: Repopulation during radiotherapy for T1 glottic cancer. Radiother Oncol 1998; 47(2): 155-159.

16. Connor NP, Cohen SB, Kammer RE, Sullivan PA, Brewer KA, Hong TS, Chappell RJ, Harari PM. Impact of conventional radiotherapy on health-related quality of life and critical functions of the head and neck. Int J Radiat Oncol Biol Phys 2006; 65(4): 1051-1062. 
17. Lee JH, Machtay M, Unger LD, Weinstein GS, Weber RS, Chalian AA, Rosenthal DI: Prophylactic gastrostomy tubes in patients undergoing intensive irradiation for cancer of the head and neck. Arch Otolaryngol Head Neck Surg 1998; 124(8): 871-875.

18. Nguyen NP, North D, Smith HJ, Dutta S, Alfieri A, Karlsson U, Lee H, Martinez T, Lemanski C, Nguyen LM, Ludin A, Sallah S. Safety and effectivenes of prophylactic gastrostomy tubes for head and neck cancer patients undergoing chemoradiation. Surg Oncol 2006; 15(4): 199-203.

19. Chen AM, Li BQ, Lau DH, Farwell DG, Luu Q, Stuart K, Newman K, Purdy JA, Vijayakumar S. Evaluating the role of prophylactic gastrostomy tube placement prior to definitive chemoradiotherapy for head and neck cancer. Int J Radiat Oncol Biol Phys 2010; 78(4): 1026-1032.

Received: March, 7, 2011

Accepted: April, 6, 2011 